Donor Financial Capacity Drives Racial Inequality in Medical Crowdsourced Funding

\author{
Mark Igra \\ igra@uw.edu \\ University of Washington
}

$3 / 17 / 2021$

Keywords: Social Networks, Stratification, Race and Ethnicity, Medical Sociology

Acknowledgements: I would like to thank Katherine Stovel and Nora Kenworthy for their assistance with this paper. 


\section{Donor Financial Capacity Drives Racial Inequality in Medical Crowdsourced Funding}

Americans facing large health-related expenses have increasingly turned to online crowdsourced funding for support, initiating 250,000 medical fundraisers on GoFundMe in 2018. Recent research indicates that these fundraisers yield inequitable outcomes, with White crowdfunding beneficiaries receiving higher levels of support than non-White beneficiaries. Researchers fear that racialized impressions of deservingness may be a driver of unequal returns in crowdfunding. However, rather than being a direct effect of interpersonal racism, differences in returns may be an indirect effect of the systemic racism that causes the social networks of Black and Hispanic Americans to have lower access to financial capital. This paper is the first to focus on how unequal access to monetary capital in networks of potential crowdfunding donors drives unequal returns for beneficiaries. I analyze a geographically stratified sample of 2,618 GoFundMe campaigns coded for perceived race and ethnicity of the beneficiary. I estimate donor financial capacity for each campaign based on the geography of Facebook friend networks and the most likely racial and ethnic makeup of the donor pool, based on donor surnames. I show that variations in the estimated income of potential donors can account for much of the deficit in returns. Thus, even in the absence of interpersonal discrimination, crowdfunding is unlikely to yield equitable outcomes given the current distribution of financial resources in the United States. 


\section{Donor Financial Capacity Drives Racial Inequality in Medical Crowdsourced Funding}

In the absence of effective government social programs, Americans facing large health-related expenses have increasingly turned to online crowdsourced funding platforms for support. The leading crowdfunding tool, GoFundMe, promises to "make it easy to inspire the world and turn compassion into action," hosting 250,000 medical fundraisers each year and raising over $\$ 650$ million dollars for medical expenses annually (GoFundMe 2019b). The rapid growth of crowdfunding has attracted the attention of researchers who worry that crowdfunding may not be an equitable method of providing financial relief for those in need. For many White Americans, opposition to public welfare programs is driven by a perception that Black and Hispanic beneficiaries are undeserving of support (Alesina, Glaeser, and Sacerdote 2001; Gilens 1999), and researchers fear that racialized impressions of deservingness may be a driver of unequal returns in crowdfunding as well. In recent work using a sample of 637 campaigns, Kenworthy et al. (2020) confirm that non-White users are indeed underrepresented on the site, and non-White beneficiaries receive fewer donations than White beneficiaries, with Black beneficiaries receiving significantly smaller average donations.

Yet despite the fact that successful crowdfunding depends on donations from family, friends and other social connections, researchers have not explicitly examined how the structure of social networks and resources available through those networks might produce inequality in medical crowdfunding returns. Rather than being a direct effect of interpersonal racism, differences in returns may be an indirect effect of current and historical systemic racism that causes the social networks of Black and Hispanic Americans to have lower access to financial capital. If differences in returns are due to racialized perceptions of deservingness, equality might be reached via attitude changes that progress generationally or due to dramatic changes in public opinion regarding racism observed in the wake of the 2020 Black Lives Matter protests (Cohn and Quealy 2020). However, if the difference in returns is due to the structure of social networks and unequal distribution of resources, solutions must be found in efforts toward broad economic equality along with institutional change that eliminates the financial distress that causes people to turn their networks for financial support.

This paper is the first to focus on how unequal access to monetary capital in networks of potential crowdfunding donors drives unequal returns for beneficiaries. I analyze a geographically stratified sample of 2,618 GoFundMe campaigns coded for perceived race and ethnicity of the beneficiary. I demonstrate that network mobilization in the form of online sharing, which does not require additional spending, does not vary based on the race and ethnicity of the beneficiary. However, Black and Hispanic beneficiaries receive fewer and smaller donations than White or Asian beneficiaries. I estimate network financial capacity using the likely residential locations of beneficiaries' Facebook friends and the most likely racial and ethnic makeup of the donor pool based on donor surnames. Using these estimates I show that that variations in the estimated income of potential donors by geography, race and ethnicity can account for much of the deficit in returns. However, variations in estimated donor financial capacity do not account for all the observed inequality. Overall, my results show that racial, ethnic and geographic disparities in network financial capacity contribute to unequal returns in network crowdfunding campaigns, and that even in the absence of discrimination, crowdfunding 
is unlikely to yield equitable outcomes given the current distribution of financial resources in the United States.

\section{Background}

American government social welfare provision is limited by design. For the first 150 years of U.S. history, individualistic ideology, distrust of government, a desire to limit aid to deserving recipients, and a fear of de-commodifying labor combined to limit government entitlements (Esping-Andersen 1990; Trattner 1998). In the wake of the Great Depression, the American welfare state grew, but in a haphazard "Rube Goldberg" fashion, with politicians using employment-based, delegated, and federalized solutions to balance Americans' desire to mitigate poverty and limit exposure to financial risks with their wariness of government intervention (Morgan and Campbell 2011).

Racism also limited the expansion of social welfare programs. When Social Security was initiated, senators from Jim Crow states blocked benefits for jobs with a high percentage of Black workers (Katznelson 2014). Even in the wake of the civil-rights movement, anti-Black sentiment and a sense that Black people disproportionally benefited from welfare drove opposition to social programs for many voters (Alesina, Glaeser, and Sacerdote 2001; Gilens 1999).

The election of Ronald Reagan, who had stoked and leveraged these sentiments, initiated the neoconservative era. Over the next three decades, policies based on individualized solutions to systemic problems resulted in the re-privatization of risk: individual retirement accounts replaced defined benefit pensions, the cost of education rose even as job security for people with higher education fell, and responsibility for medical spending shifted to individuals even as costs skyrocketed (Hacker 2008).

The Affordable Care Act represented a substantial reversal of this trend, but "Obamacare" still reflects the Rube Goldberg nature of the American social welfare system: coverage is tied to employment, benefits are unevenly distributed, and outsize risks can be borne by individuals who fall between the cracks. In 2017, 28.5 million people in the United States still did not have health insurance (Berchick, Hood, and Barnett 2018). For those with insurance, high deductibles often strain family budgets. In 2016, 45 million American adults were covered by an insurance plan with a deductible of at least $\$ 1,000$, and of those, $38 \%$ reported having medical debt or problems paying medical bills (Collins, Gunja, and Doty 2017). Adding to the financial burden of American families facing illness, the U.S. offers no wage support to those who miss work due to personal or family illness (Alesina, Glaeser, and Sacerdote 2001).

In the absence of an effective government social safety net, Americans have been increasingly turning to what Rob Solomon, former CEO of crowdfunding leader GoFundMe, called the "digital safety net" of online medical crowdfunding (Harris 2017). Despite the "digital" and "crowd" branding, this new safety net is highly dependent on pre-existing social relationships. While GoFundMe promises that campaigns can "inspire the world," it recognizes that friends and family are the most likely donors, and urges organizers to link their campaigns to Facebook accounts, warning "If you aren't sharing your campaign with your friends and family, then it's likely not going to get donations" (GoFundMe 2019a).

Medical crowdfunding has attracted the attention of health researchers who fear that a privately-run service allowing people to appeal to social networks for funding is an inequitable 
tool for addressing healthcare needs (Snyder 2020; Snyder, Mathers, and Crooks 2016; Young and Scheinberg 2017). Scholars have identified a number of potential sources of inequality in crowdsourced funding including barriers to entry, technological factors, policy effects, and a central concern with how perceptions of deservingness affect crowdfunding outcomes (Snyder, Mathers, and Crooks 2016). Crowdfunding organizers have to overcome significant barriers to entry including access to high-speed internet, social media skills and a bank account into which the crowdfunding provider can deposit credit-card donations. ${ }^{1}$ Studies have shown that use of medical crowdfunding is concentrated among those with existing privileges. Among medical crowdfunding beneficiaries, White Americans are over-represented as are residents of higher income locations in both Canada (Duynhoven et al. 2019) and the United States (Lee and Lehdonvirta 2020). Even for those who clear technological barriers to entry, technology continues to play a role in crowdfunding success because promotion of campaigns on crowdfunding and social media sites is controlled by unaccountable proprietary algorithms. Researchers also worry that by shifting norms from distribution according to need to distribution according to perceived deservingness, crowdfunding allows policy makers to avoid addressing systemic failures in providing for the most needy (Kenworthy 2019; Snyder, Mathers, and Crooks 2016).

As Skocpol (1992) has argued, the lack of universal social programs in the United States is a product of a desire limit support to those viewed as "deserving." A large portion of research into crowdfunding has explored how private giving is also shaped by perceptions of which beneficiaries deserve help. In a qualitative analysis of 200 campaigns, Berliner and Kenworthy $(2017,230)$ observe that the "constellation of signifiers that position campaigns as deserving," includes attributes of the beneficiary themselves along with the effective use of symbolic language, branding and media. One signifier of deservingness is the nature of the medical condition itself. Loeb et al. (2018) find that GoFundMe campaigns on behalf of people with breast cancer request and receive substantially more support than those for prostate cancer in terms of both absolute dollars and percent of goal. Similarly, campaigns supporting gendertransition surgery receive less money and a smaller proportion of their goal than general medical campaigns (Barcelos 2019). Other signifiers may be be reflected in the content of the text and photographs with the campaign. Medical transition campaigns attempt to communicate deservingness by emphasizing that beneficiaries are hard-working and warm-hearted (Barcelos 2019). Rhue and Robert (2018) explore the role of projected emotion in fundraising success, linking success to positive emotional valence of both the text and the photos posted by the requesters.

In the United States, race may be another signifier of who is deserving of social support. Writing about Tea Party Republicans, Skocpol $(2012,74)$ observed that for this politically ascendant group, "deservingness is a cultural category, closely tied to certain racially and ethnically tinged assumptions about American society in the early twenty-first century." If these racialized perceptions of deservingness apply to potential private donors, crowdfunding campaigns are likely to yield lower returns to groups on the wrong side of those "racially and ethnically tinged assumptions" about who is deserving. Kenworthy et al. (2020) find that all nonWhite beneficiaries receive fewer donations than White men, and Black beneficiaries receive fewer donations of smaller average value. The authors conclude that "crowdfunding is playing host to, and potentially exacerbating, social biases related to perceived deservingness; however,

\footnotetext{
${ }^{1}$ Crowdfunding providers deduct credit card processing fees which constitute the bulk of their revenue.
} 
much more research is needed to better understand how these disparities are created, and the social and technological mechanisms through which they are sustained and compounded" (Kenworthy et al. 2020, 18).

This paper begins to address the mechanisms behind disparate results by turning the focus away from crowdfunding beneficiaries and onto the networks of potential donors whose actions are directly responsible for crowdfunding success. Research into networks and medical crowdfunding to date indicates that many campaigns make explicit appeals to friends and families, that success depends on online sharing, and that county-level variation in income is reflected in returns (Lee and Lehdonvirta 2020; Snyder et al. 2017). The work I present here uses granular estimates of network financial capacity based on social geography and estimated racial homophily in the donor pool of each campaign to evaluate the extent that racial inequality in crowdfunding is a product of structural inequality in the distribution of financial resources in the United States.

\section{Crowdfunding as a Network Process}

In and of themselves, social networks are neutral structures, but when they are used to access information, opportunities, or money, networks can amplify or ameliorate existing inequalities. While social capital can yield valued benefits in poor communities (Portes and Sensenbrenner 1993; Stack 1975), such networks may be less effective either because network alters do not have the needed resources, because they are less likely to share scarce resources they have, or because they cannot expect reciprocity (Lubbers, Small, and García 2020). Network-driven inequality has been particularly well studied in the domain of employment search (Granovetter [1974] 1995; McDonald 2011; McDonald et al. 2016; Pedulla and Pager 2019; S. Smith 2000; 2005), and my study of network inequality in crowdfunding builds on the concepts established in that field.

Access to valued resources via social networks depends on connections to network alters who can supply those resources. When members of marginalized groups belong to segregated homophilous networks, they have lower access to resources that are controlled by dominant groups. For example, even when receiving the same number of job leads, Black job seekers receive fewer leads for supervisory jobs (McDonald, Lin, and Ao 2009), and access to professional jobs leads has been shown to be dependent on membership in an "old boys" network composed primarily of White men (McDonald 2011). While Granovetter (1973) famously argued that weak ties could allow access to people with resources beyond those available among strong ties, racial homophily among weak ties is about the same as among strong ties (DiPrete et al. 2011), and weak ties have been shown to be effective in job search only for White men who have access to influential contacts (S. Smith 2000).

Even when marginalized groups appear to have equal access to network resources, differences in network mobilization can yield unequal outcomes. Pedulla and Pager (2019) find that access to network resources, in this case information about available jobs, does not explain inequality between Black and White job seekers who use networks to find jobs. Instead, referrers for White job seekers were more advantageously positioned within hiring firms, and Black job seekers were less able to mobilize their connections. The financial and social precarity of marginalized groups can also lead to differences in network mobilization. Smith (2005) found that marginalized Black workers demonstrated "defensive individualism," and were less likely to refer peers for jobs because they felt their own positions might be in jeopardy. 
Of course, social networks may also yield unequal outcomes due to simple racial discrimination on the part of people who control the resources being sought. Substantial research shows that discrimination in hiring remains a barrier to employment (Pager 2003; Pager and Shepherd 2008; Quillian et al. 2017; Quillian, Lee, and Oliver 2020), and experimental evidence shows that employer prejudice can shape network-based hiring decisions based on the race of the applicant and the race of the network referrer (Silva 2018).

Given the prior research on the uses of networks in job search, any study of disparate network outcomes by race should consider the roles of network access, network mobilization, and the possibility of discrimination on outcomes.

\section{Processes of Network Inequality in Crowdfunding}

The concepts of network access and mobilization can be leveraged when building a model of network efficacy in GoFundMe. The success of a medical crowdfunding campaign depends on access to a large network of potential donors, the financial capacity of potential donors to give to the campaign, and the mobilization of potential donors to share and donate to the campaign. In this case, I define network access in terms of the (unmeasured) number of potential donors, that is, the number of people who become aware of the campaign by any mechanism. The term "financial capacity" refers to the income or wealth of potential donors. Returns from those donors are most meaningfully defined in terms of money raised. Mobilization of the network, the link between access and returns, is captured by sharing and donations. It is worth noting, however, that the number of potential donors (network access) is dependent on mobilizing some set of potential donors to share the campaign.

Network access is driven by the organizer's first-degree online and offline social network connections, and the amount of sharing done by others in the potential donor network. The size of the campaign organizer's first-degree network directly shapes the number of people who see a campaign. Organizers who have large online friend networks can expect a minimum number of online "impressions." The number of new potential donors will increase with additional online social network sharing; more sharing is associated with greater access. The average number of new potential donors reached by each share depends on network structure. In a dense network with many overlapping ties, additional sharing will tend to reach the same people, while in a lower density network with the same degree, more new potential donors will be reached with every share.

Turning to network mobilization, two abstract factors might cause a potential donor to share the campaign. First, the stronger the social tie between the potential donor and the beneficiary, the more likely donors are to share the campaign. Second, a sense that the beneficiary is "deserving" of aid will mobilize potential donors to take action on the beneficiary's behalf. Deservingness and tie strength also shape decisions to donate to the campaign, but their effects on returns are moderated by a third factor: money available to donate to a campaign.

Tie strength, or the relationship between the donor and the beneficiary, can affect mobilization in a number of ways. In the case of close emotional attachment between the donor and beneficiary, the donor will be more likely to donate and share for simple affective reasons: we want to help the ones we love. Monetary payments and public sharing also convey meaning both to the beneficiary and the broader community (Zelizer 1997). For direct ties, these donations demonstrate the commitment of the donor to the beneficiary and may strengthen their 
relationship. In situations with dense, overlapping, strong ties, public donations also demonstrate to the community that the donor is doing their part to support fellow community members. Given equal access to monetary capital we would expect people with closer ties to the participant to donate more frequently and in greater amounts.

Potential donors are more likely to take action on behalf of a campaign beneficiary if they view the campaign as deserving. Campaigns on behalf of children may be viewed as deserving given the contemporary sense of the "priceless" nature of modern childhood, and the priority given to public social support for children and their mothers (Skocpol 1992; Zelizer 1994). Or, as demonstrated in prior studies of medical crowdfunding, the nature of the disease or disability may be a marker of deservingness (Barcelos 2019; Loeb et al. 2018). The magnitude of the burden placed on the beneficiary and their family may be interpreted in terms of deservingness: if the need is large, potential donors may feel the beneficiary warrants more support. ${ }^{2}$ This paper examines another important factor that may affect perceptions of deservingness, the perceived race and ethnicity of the beneficiary. A presumption that perceived deservingness is unrelated to the perceived race and ethnicity of the beneficiary leads to my first hypothesis regarding differences in returns by race and ethnicity. Hypothesis la: Sharing of campaigns does not vary based on the race and ethnicity of the recipient. The observation that sharing of campaigns depends on deservingness but not on network financial capacity leads to Hypothesis 1b: Sharing of campaigns does not vary based on the financial capacity of recipients' networks.

Network Financial Capacity and Returns. The aim of crowdfunding is to raise money for a beneficiary, so the financial resources of potential donors are a key determinant of the success of a campaign. While the conceptual model presented here posits that the decision to donate is affected by tie strength and deservingness, regardless of how close and deserving they find the beneficiary, donors without sufficient financial capacity simply cannot make large donations.

If networks tend to include many potential donors with similar financial resources, individual decisions of potential donors will combine to yield measurable differences in total returns to campaigns. For networks predominantly populated by people with substantial financial capacity, one would expect some large donations from strong ties, and many donations from weak ties. Conversely, potential donors with low financial capacity might provide small donations to strong ties as an expression of solidarity, and simply forgo donations to those with whom they have weak ties. As a result, beneficiaries embedded in high-financial-capacity social networks would tend to receive a greater number of donations and larger average donation sizes than beneficiaries embedded in low-financial-capacity networks, given equal network size.

In summary, campaigns perceived as equally "deserving" may receive very different numbers of donations or different average donation amounts based on the financial capacity of their network. The link between financial capacity and donations suggests Hypothesis 2: The number of donations to campaigns is positively associated with network financial capacity, and Hypothesis 3: The size of donations is positively associated with network financial capacity.

Social network structure and network financial capacity. The conceptual model presented thus far argues that if potential donor networks are composed of people with similar financial resources, individual decisions about donations combine to yield disparate outcomes for

\footnotetext{
${ }^{2}$ Note that the amount of money raised and amount of money requested may also be correlated if campaigns raise their requests after they have proved successful. In this case, the higher goal likely captures other unmeasured qualities of the campaign that cause donors to view the beneficiary as deserving donations.
} 
beneficiaries. Though there is no way to directly establish the financial resources available to members of a potential donor network, correlations between established patterns of network homophily and patterns of economic inequality imply that financial resources will tend to be correlated within a given network of potential donors, especially among the vast majority of campaigns that fail to "go viral." In particular, geographic, racial and ethnic homophily, combined with patterns of geographic and ascriptive income inequality, provide a basis for estimating network financial capacity and modeling its impact on returns.

Social geography and donor financial capacity. Even in the age of online social media, physical proximity is a strong determinant of "friendship" in online social networks. The most extensive dataset describing the geographic distribution of online friends is the Facebook Social Connectedness Index (SCI), which characterizes the relative number of online friendship ties between geographic areas (Bailey et al. 2018). Facebook data aggregated to the county level shows high levels of geographic homophily: for residents of a typical county, more than half of all Facebook friends live within 50 miles, even though only $0.7 \%$ of U.S. residents live within that radius (Bailey et al. 2018). However, county-level income estimates may not be particularly precise indicators of network financial capacity. Within metropolitan areas, the distribution of Facebook friends is correlated with more localized patterns. In New York City, people living in high-income zip codes have more geographically dispersed Facebook friend networks than those living in poorer zip codes, and the number of connections between zip-codes is correlated with the similarity of incomes (Bailey et al. 2019).

Racial homophily and donor financial capacity. Decades of research has documented that racial homophily occurs in a wide range of networks. Within-race network connections occur at a much higher rate than chance in core discussion networks, workplace networks, school networks and online social networks (DiPrete et al. 2011; McPherson, Smith-Lovin, and Cook 2001; Moody 2001; J. A. Smith, McPherson, and Smith-Lovin 2014; Wimmer and Lewis 2010). In contrast to expectations of the diversity of weak ties, extended acquaintanceship networks also tend to be segregated by race and ethnicity (DiPrete et al. 2011).

The critical insight for understanding disparity in GoFundMe campaigns is that racial and ethnic homophily in networks is associated with inequality in network financial capacity, because homophily occurs in tandem with profound racial and ethnic economic inequality in the U.S. Black and Hispanic U.S. residents have less monetary capital, on average, than nonHispanic White and Asian U.S. residents. In 2018 Black families had the lowest median household income $(\$ 40,258)$ of the Census Bureau's four major race and ethnic categories, while Hispanic families had somewhat higher median household incomes of $\$ 50,486$. Asian $(\$ 81,331)$ and White non-Hispanic $(\$ 68,145)$ households had substantially higher median incomes (U.S. Census Bureau 2018). These income differentials are quite large, but the history of institutional racism in the United States means that household wealth stratification is even larger: in 2016, median wealth held by non-Hispanic White families $(\$ 171,000)$ was 10 times higher than that of Black families $(\$ 17,600)$ and more than eight times higher than the $\$ 20,700$ median for Hispanic families (Detting et al. 2017).

In spite of these overall patterns, the extent of racial and ethnic economic inequality varies regionally. For example, the median income for Black households is $77 \%$ of White household income in Dover Delaware $(\$ 44,000 / 57,000)$ and $26 \%$ in San Francisco $(\$ 30,000 / 116,000)$. Thus, to effectively estimate donor financial capacity, we must account for the geographic distribution of potential donors, the racial and ethnic makeup of the donor pool, 
and the combination of these two factors for the relevant set of donors. I explain how I combine geographic and racial income variation to estimate donor financial capacity in my methods section below.

\section{Data and Methods}

Many of the concepts central to the framework outlined above are not directly observed on the GoFundMe platform, so I begin this section with a short overview of how I operationalize those concepts. My analysis integrates four data sources: data scraped from 2,618 GoFundMe medical crowdfunding campaigns, including information about 412,837 individual donations; online raters' estimates of the race, ethnicity, gender and age of beneficiaries for each campaign; geocoded population and income data from the American Community Survey; and surname frequency tables from the U.S. Census Bureau.

The size of the potential donor pool cannot be directly determined. However, at the time I collected the data, GoFundMe pages included the number of online Facebook friends of the campaign organizer along with a count of social media shares. While offline network size, and the density and average degree of the online network are not known, these properties are correlated with population size, and I include log local population size as an independent variable.

I do not attempt to build a synthetic measure of deservingness, but my models include covariates that may contribute to perceptions of deservingness. Models include a binary covariate for child beneficiaries (rated age under 18), and a covariate for the campaign's monetary goal which I treat as an indicator of the burden faced by the family.

Neither the race and ethnicity of donors, nor the race and ethnicity of beneficiaries can be estimated with complete confidence. I used human raters to estimate the race and ethnicity of beneficiaries and employ probabilistic estimates of donor race and ethnicity based on surnames, as detailed below. My estimates of network financial capacity combine zip-code level geographic distributions for online friends from Facebook Social Connectedness Index with median household income data by race and ethnicity.

\section{Data Overview}

I initiated searches of the GoFundMe website between February 2 and February 23, 2019, using city names as search terms. Search terms included the names of the 100 largest cities in the United States plus the two largest cities in each state if they were not included in that set. My web scraping code scanned the first 200 campaigns returned per search and downloaded data for campaigns that had been active in the prior year. This yielded 18,817 distinct campaigns of which 6,186 were in GoFundMe's medical category.

The set of 6,186 medical campaigns was filtered in a number of steps to arrive at the 2,618 campaigns used in this analysis. Because campaigns with goals $<=\$ 100$ appear to use their goal as a placeholder and campaigns over $\$ 10$ million do not benefit a single individual, I removed 104 campaigns with these very large and small goal amounts along with a single outlier that received national news coverage and more than 5 times the number of shares of any other campaign. I then retained the set of 3,372 campaigns that had Facebook friend counts available 
and had been online for at least 5 weeks. ${ }^{3}$ The final sample includes only campaigns still available online when I re-scraped the data 6 months after the original access to update money raised.

\section{Operationalizing Variables}

Race and gender identification of beneficiaries. Despite the use of an independent variable labelled 'beneficiary race/ethnicity' it is important to be clear about what is being measured in this paper. Though the text of this document often refers to beneficiaries' race, that should be considered a shorthand for "race and ethnicity as perceived by two Amazon Mechanical Turk raters." This subjective evaluation of beneficiary race depends both on the photos and text presented in the campaign and how socially constructed racial categories have been internalized by the rater, much as it would for potential donors who do not know the beneficiary. Prior research has shown that observers' racial classification of subjects based on photos matches the subject's self-perception of race at a rate higher than $90 \%$ when observers view images of people who consider themselves White or Black, $80 \%$ for those who consider themselves Latino and lower levels for people who perceive themselves as mixed race (Feliciano 2016). For this study raters were told to review photographs and read the full text of the campaign to evaluate the race age and gender of beneficiaries and to use names as potential markers of Hispanic ancestry. Race and ethnicity were coded as 'hispanic' if ethnicity was marked as 'Hispanic', with 'white', 'black', 'asian' and 'other' assigned for campaigns where the beneficiary is marked as "Not Hispanic." Agreement among raters was $93 \%$ on gender and $80 \%$ on race/ethnicity. If the two raters did not match on the primary variables on race/ethnicity and gender I personally adjudicated the discrepancy by examining the campaign. Models estimated using only campaigns where the online raters agreed on race and ethnicity showed very similar coefficients to models estimated using all campaigns.

Estimating Donor Homophily. Racial and ethnic homophily in American social networks is a well-established pattern, but this pattern has not been confirmed for networks of donors to crowdfunding campaigns. While perceived race and ethnicity of the beneficiary is directly coded from photos and other information in the campaign, we know little about the identity of donors, other than their names. Donors may choose to attribute their donations to "Anonymous," and there is no guarantee that stated donor names match the name of the actual donor. However, donors - especially those known to the recipient — have an incentive to provide accurate names in order to demonstrate support for the recipient. Seventeen percent of the 412,837 donations to the campaigns in this study are listed as "Anonymous" or a variant, while the remaining $83 \%$ are listed with a name.

Among those donors with listed names, I take advantage of the fact that the prevalence of surnames varies by race and ethnicity. I use the U.S Census Bureau list of prevalence of 167,613 surnames by race and ethnicity to estimate the probable racial and ethnic mix of the donor pool for each campaign. Seventy two percent of all donations included a surname that matched a name included in the census list. I perform maximum likelihood estimation for each campaign to find the most likely racial makeup of a pool of donors yielding the specific surnames of donors to the campaign. This likelihood is constrained by a prior expectation that the pool matches the

\footnotetext{
${ }^{3}$ The 5 -week cutoff was chosen because preliminary analysis showed most campaigns received no more donations after that time.
} 
makeup of the U.S. population, except that homophily with the perceived race of the recipient is allowed to vary without limit.

As illustrated in Figure 1, campaigns show substantial racial homophily, with same-race donors over-represented compared to U.S. population proportions (dotted lines) for the large majority of campaigns. The median campaign for a Black or Hispanic beneficiary receives approximately three times the number of donors from the same race and ethnicity as would be expected in random mixing. For Asian recipients the median percentage of Asian donors is over eight times what would be expected from random mixing. Non-Hispanic White recipients have a median estimated donor pool of $88 \%$ non-Hispanic White donors, compared to the roughly $60 \%$ of the overall U.S. population.

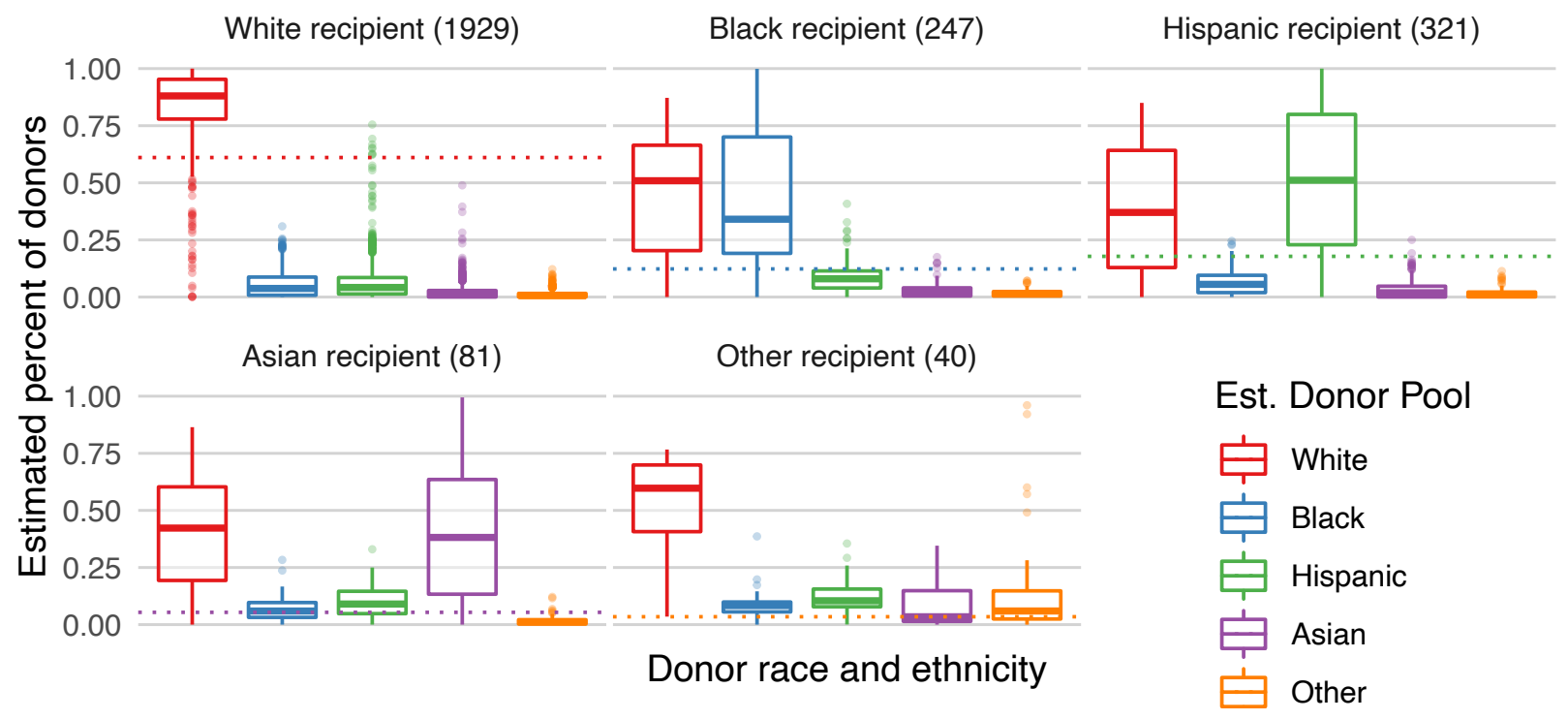

Figure 1: Estimated distribution of donor race for campaigns, by perceived race and ethnicity of recipient.

Operationalizing Network Financial Capacity. Statistical modeling of crowdfunding has often included covariates derived from the demographics of the administrative geography surrounding the location where the campaign is based (Duynhoven et al. 2019; Lee and Lehdonvirta 2020). Because my focus is on the resources available to donors, I instead derive covariates using a synthetic social geography based on the locations where friends of the campaign organizer are likely to live. Although campaign donors need not be first-degree friends of the organizer, a social geography based on Facebook friendship is a reasonable choice for estimating donor financial capacity because most campaigns receive donations from a relatively small number of people. The median campaign in my sample receives only one donation for every 7 first-degree friends of the organizer, and $90 \%$ of campaigns receive fewer donations than the number of firstdegree friends. 


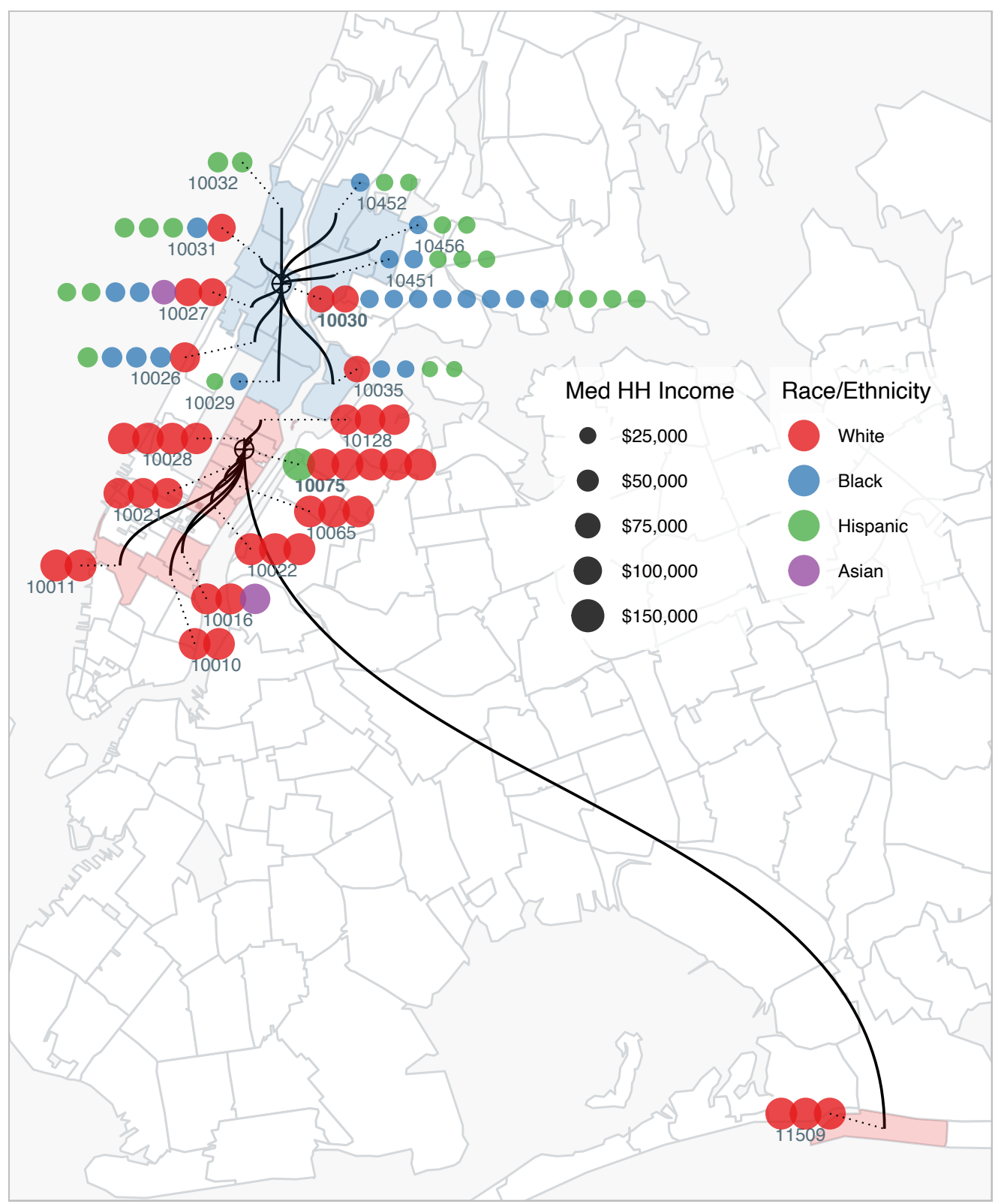

Figure 2: This map highlights the 10 zip-code tabulation areas most likely to contain Facebook friends for residents of zip codes 10030 (Harlem) and 10075 (Upper East Side) in New York City. The number and expected race and ethnicity of alters shown is based on census population estimates and Facebook friend distributions for networks of equal total size. None of the top 25 zip-codes for friends is shared between these nearby locations. Donor financial capacity is computed by weighting median incomes by proportion of friends expected across all zip codes.

I construct a synthetic geography corresponding to each U.S. zip code tabulation area (ZCTA) using the ShareFriends metric introduced by Bailey $(2017 ; 2019)$ along with household income and population data from the U.S. census. ShareFriends $\mathrm{zz}_{\mathrm{z}}$ is an approximate proportion of Facebook friends of people in ZCTA $z$ who live in ZCTA z', computed for 26,266 ZCTAs that 
account for $99.4 \%$ of the U.S. population. ${ }^{4}$ I define the donor financial capacity for social geography $s$, corresponding to the locations where friends of residents ZCTA z live, as the median household income in each ZCTA z', weighted by the share of friends who live in that ZCTA:

$$
D F C_{s}=\sum_{z^{\prime} \in Z} \text { ShareFriends } s_{z, z^{\prime}} \text { Inc }_{z^{\prime}}
$$

For each ZCTA, I also compute a measure of financial capacity of a donor pool for each racial and ethnic group, which I use to estimate financial capacity for pools of donors matching the estimated racial makeup of donors to each campaign. It would be incorrect to simply substitute the median household income for a racial and ethnic group $\left(I n c_{r z^{\prime}}\right)$ in each ZCTA into the formula above because different ZCTAs have very different ethnic and racial composition. To compute the expected financial capacity of donors of race and ethnicity $r$ who are friends of residents of ZCTA $z$, I compute a weighted income for that race and ethnicity across all ZCTA's $z$ ' where friends reside:

$$
D F C_{r, s}=\sum_{z^{\prime} \in Z} w_{r, z^{\prime}} \text { Inc }_{r, z^{\prime}}
$$

Here the weights $w_{r z}$ ' represent the percentage of all friends of race and ethnicity $r$ who live in $z^{\prime}$, under the assumption that the geographic distribution of friends by race and ethnicity is proportional to their residential population distribution. The assumption of independence allows $w_{r, z^{\prime}}$ to be computed as the product of (ShareFriends $s_{z z^{\prime}}$ ) with the proportion of residents of $z^{\prime}$ of race $\mathrm{r}\left(\right.$ Population $_{\mathrm{rz}} /$ Population $_{\mathrm{z}}$ ), normalized to sum to 1 . Figure 2 illustrates the process, focusing on two New York city locations and highlighting the ten most socially connected ZCTAs for each of them.

To estimate donor financial capacity for each campaign accounting for both social geography and homophily, I use estimated proportions of each racial and ethnic group in the donor pool to weight race-specific financial capacity $\left(\mathrm{DFC}_{\mathrm{r}, \mathrm{s}}\right)$ for the social geography corresponding to the ZCTA where the campaign was initiated.

Estimated network financial capacity varies substantially as shown in in Figure 3. The left panel shows distributions computed only using income variation by social geography, calculated from the 1269 distinct ZCTAs where campaigns were initiated. Even without considering the possibility of racial and ethnic homophily in donor networks, geographically estimated donor income levels differ by beneficiary race. Black beneficiaries are more likely to live in lower-income areas that are socially connected to other lower-income areas, while campaigns on behalf of Asian beneficiaries tend to be initiated in higher income areas. These income differentials increase when estimates account for the estimated racial makeup of each campaign's donor pool as shown in the right-hand panel of the figure.

${ }^{4}$ Facebook does not provide SCI for 6 of the ZCTAs in my sample (seven campaigns), so I substitute income estimates for the surrounding core-based statistical area. Removing these campaigns does not substantively change results. 


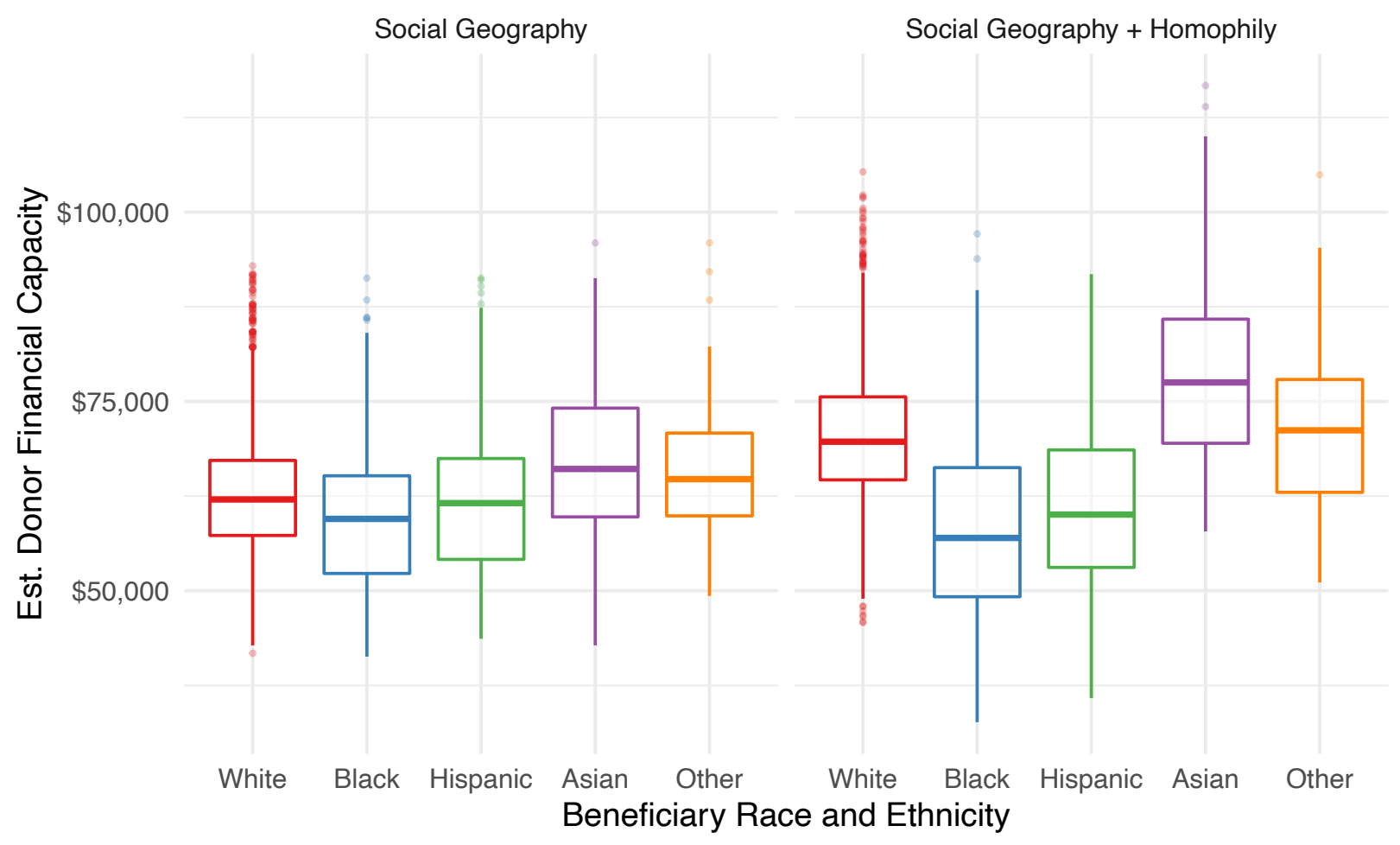

Figure 3: Estimated donor financial capacity for campaigns.

These estimates of donor financial capacity are clearly imperfect. The ShareFriends metric provides friend locations averaged across all residents of a ZCTA, rather than for a particular campaign organizer. Similarly, income estimates are based on census figures for entire ZCTAs. In addition, wealth inequality may be an important driver of unequal returns, and I do not account for wealth in my estimates of financial capacity. Given these limitations, model coefficients should be evaluated cautiously, focusing on the strength of their association with outcomes and their ability to improve model fit when compared with models that do not account for social geography or homophily. I supply comparisons with alternate estimates as robustness checks.

\section{Descriptive Statistics}

Descriptive statistics, including rated race, ethnicity and gender of beneficiaries are shown in Table 1 . White beneficiaries, $73.7 \%$ of the sample, are overrepresented compared to the U.S. population as a whole (60.1\%), and Black, Hispanic, and Asian beneficiaries are underrepresented. Kenworthy et al. (2020) also found that Black beneficiaries were underrepresented in their randomly selected sample of medical crowdfunding campaigns. 
Tables and Figures

Table 1: Descriptive statistics by perceived race and ethnicity of beneficiary.

\begin{tabular}{|c|c|c|c|c|c|c|c|}
\hline & White $(\mathrm{N}=1,929)$ & Black (N=247) & Hispanic $(\mathrm{N}=321)$ & Asian $(\mathrm{N}=81)$ & Other $(\mathrm{N}=40)$ & Total $(\mathrm{N}=2,618)$ & $\mathrm{p}$ value \\
\hline Gender & & & & & & & 0.621 \\
\hline Female & $1,028(53.3 \%)$ & $122(49.4 \%)$ & $162(50.5 \%)$ & $45(55.6 \%)$ & $23(57.5 \%)$ & $1,380(52.7 \%)$ & \\
\hline Male & $901(46.7 \%)$ & $125(50.6 \%)$ & $159(49.5 \%)$ & $36(44.4 \%)$ & $17(42.5 \%)$ & $1,238(47.3 \%)$ & \\
\hline Child $(<18)$ & & & & & & & 0.476 \\
\hline FALSE & $1,532(79.4 \%)$ & $196(79.4 \%)$ & $246(76.6 \%)$ & $68(84.0 \%)$ & $29(72.5 \%)$ & $2,071(79.1 \%)$ & \\
\hline TRUE & $397(20.6 \%)$ & $51(20.6 \%)$ & $75(23.4 \%)$ & $13(16.0 \%)$ & $11(27.5 \%)$ & $547(20.9 \%)$ & \\
\hline Goal (\$) & & & & & & & 0.010 \\
\hline Median & 15,000 & 10,000 & 10,000 & 20,000 & 27,500 & 15,000 & \\
\hline Mean (SD) & $31,282(48,632)$ & $35,364(61,519)$ & $28,451(53,488)$ & $45,845(72,453)$ & $49,638(80,970)$ & $32,051(52,152)$ & \\
\hline Q1, Q3 & $8,000,35,000$ & $5,000,45,000$ & $5,000,30,000$ & $10,000,50,000$ & $10,000,50,000$ & $7,500,35,000$ & \\
\hline Facebook friend count & & & & & & & $<0.001$ \\
\hline Median & 549 & 759 & 541 & 589 & 556 & 565 & \\
\hline Mean (SD) & $771(801)$ & $1,234(1,272)$ & $749(781)$ & $755(715)$ & $770(818)$ & $811(862)$ & \\
\hline Q1, Q3 & 303,909 & $382,1,568$ & 282,920 & 315,933 & 292,963 & 305,960 & \\
\hline Number of times shared & & & & & & & 0.358 \\
\hline Median & 520 & 528 & 492 & 474 & 557 & 517 & \\
\hline Mean (SD) & $876(1,250)$ & $1022(1,750)$ & $843(1,148)$ & $769(800)$ & $1,020(1,212)$ & $885(1,282)$ & \\
\hline Q1, Q3 & $239,1,081$ & $260,1,038$ & 231,932 & $262,1,034$ & 302,1440 & $242,1,061$ & \\
\hline Number of donations & & & & & & & 0.003 \\
\hline Median & 86 & 76 & 65 & 88 & 92 & 83 & \\
\hline Mean (SD) & $155(244)$ & $161(242)$ & $122(295)$ & $252(717)$ & $208(315)$ & $155(279)$ & \\
\hline Q1, Q3 & 41,179 & 32,168 & 28,132 & 42,193 & 48,218 & 38,171 & \\
\hline Amount raised (\$) & & & & & & & $<0.001$ \\
\hline Median & 7,805 & 4,920 & 4,630 & 7,295 & 8,496 & 7,118 & \\
\hline Mean (SD) & $14,693(20,897)$ & $11,315(16,237)$ & $9,424(15,125)$ & $19,238(37,302)$ & $16,952(22,818)$ & $13,903(20,720)$ & \\
\hline Q1, Q3 & $3,175,17,840$ & $1,625,13,628$ & $1,800,10,915$ & $3,708,16,531$ & $3,605,23,450$ & $2,778,16,600$ & \\
\hline Average donation size (\$) & & & & & & & $<0.001$ \\
\hline Median & 86 & 61 & 71 & 86 & 82 & 82 & \\
\hline Mean (SD) & $95(47)$ & $69(41)$ & $78(38)$ & $98(64)$ & $97(101)$ & $90(48)$ & \\
\hline Q1, Q3 & 65,112 & 43,86 & 52,96 & 59,116 & 59,102 & 61,108 & \\
\hline
\end{tabular}


The distributions of key variables from the campaigns tends to be highly skewed and distributed in an approximately log-normal fashion, as illustrated in the log-scale histograms in Figure 4. I use log transformed versions of these variables in my models.

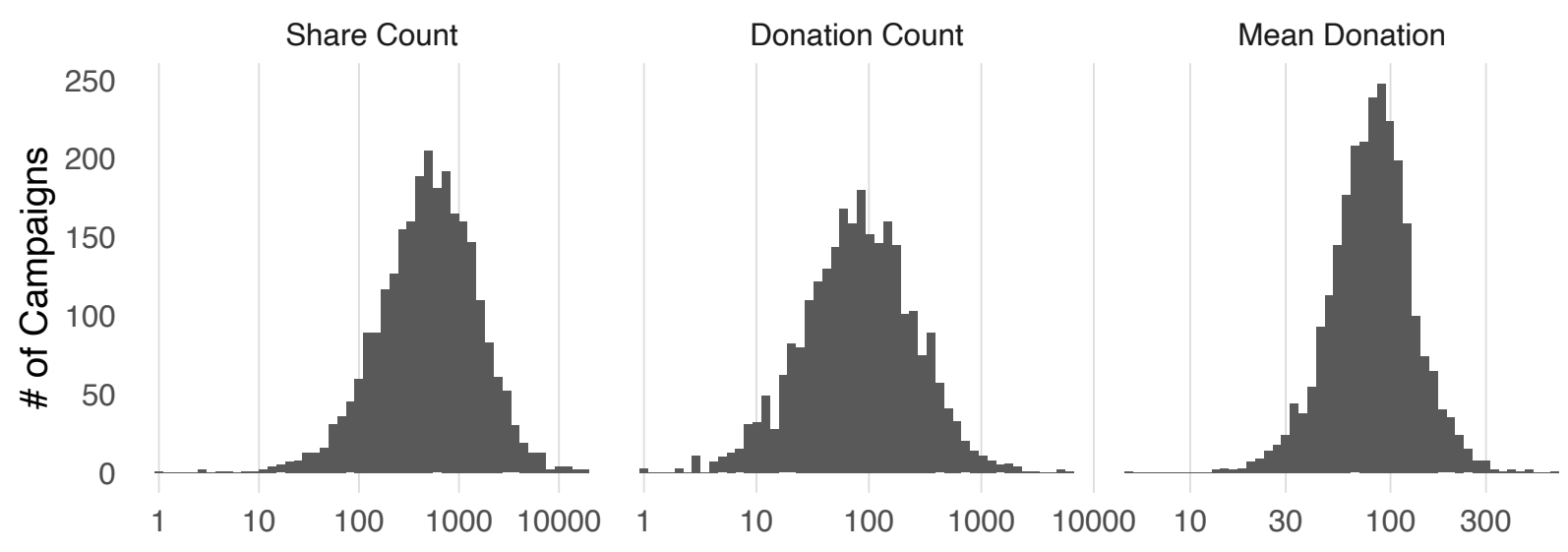

Figure 4: Distributions of dependent variables for campaigns. Log scales.

The distribution of individual donation amounts is also skewed. While the vast majority (88.4\%) of the 412,837 donations in this data set are for amounts of $\$ 100$ or less, larger donations account for half of the dollars donated (51.7\%). Donations of $\$ 1000$ or more account for $19.6 \%$ of the funds raised, but only $1.2 \%$ of donations. While charitable fundraising often exhibits skewed donation distributions, for this research the pertinent question is whether high dollar donations are evenly distributed by beneficiary race and ethnicity. They are not. Fortynine percent of campaigns on behalf of White and Asian recipients received at least one donation of $\$ 1000$ or more, compared to only $36 \%$ of those on behalf of Black or Hispanic beneficiaries.

\section{Statistical Models}

I test my hypotheses with mixed effect hierarchical models that include a random intercept for the census Core Based Statistical Area (CBSA) of the individual initiating each campaign.

\section{Results}

Figure 5 reports results from models predicting amount raised, with $95 \%$ confidence intervals around parameter estimates. Controls have similar coefficients in each model, but model 2 shows large and significant deficits in fundraising for Black, Hispanic and "other" race beneficiaries. The dependent variable is in log form, so coefficients represent multiplicative changes in outcomes. Translating model 2 estimates into specific predictions, a White man in Seattle who requested $\$ 15,000$ would be expected to raise $\$ 7,591$, whereas a Black man from the same zip code would receive $\$ 4,891$ and a Hispanic man $\$ 4,756$. 
17 Donor Financial Capacity Drives Racial Inequality in Medical Crowdsourced Funding

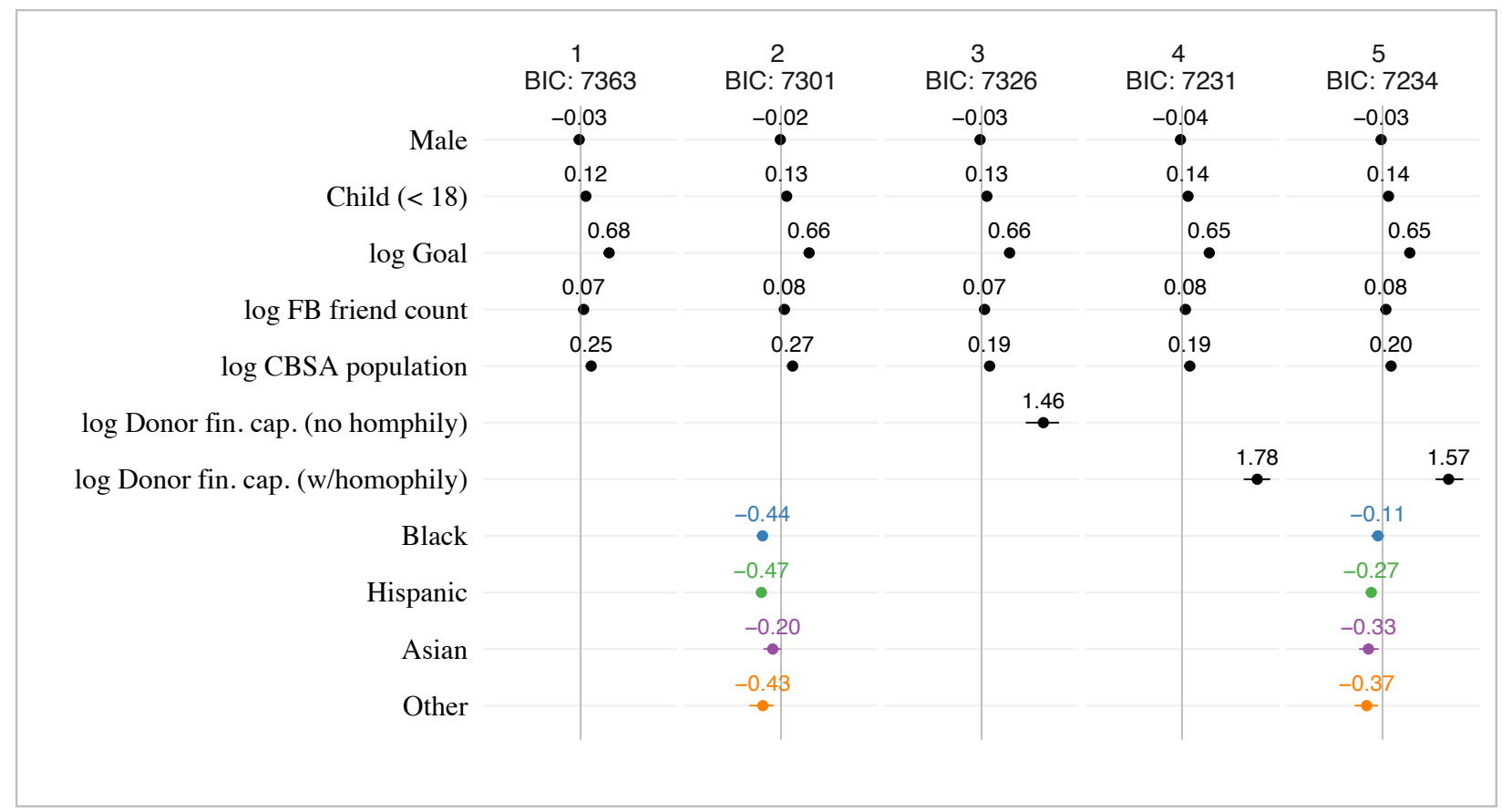

Figure 5: Summary of hierarchical linear models estimating log total money raised with bootstrap 95\% confidence intervals.

The full impact of financial capacity on returns can be seen in model 5 . Here the magnitude of the negative coefficient for Black recipients is reduced by $75 \%$ and is no longer significant at traditional levels, and the coefficient for Hispanic recipients shrinks by more than $40 \%$ compared to models that ignore financial capacity. After accounting for higher donor financial capacity, returns to Asian recipients are lower than those for White recipients at traditional levels of significance.

The disparities in returns shown in model 2 can be explained by differences in access to potential donors or by differences in mobilization of potential donors to donate funds. I examine these factors and their relationship to network financial capacity in turn. 
18 Donor Financial Capacity Drives Racial Inequality in Medical Crowdsourced Funding

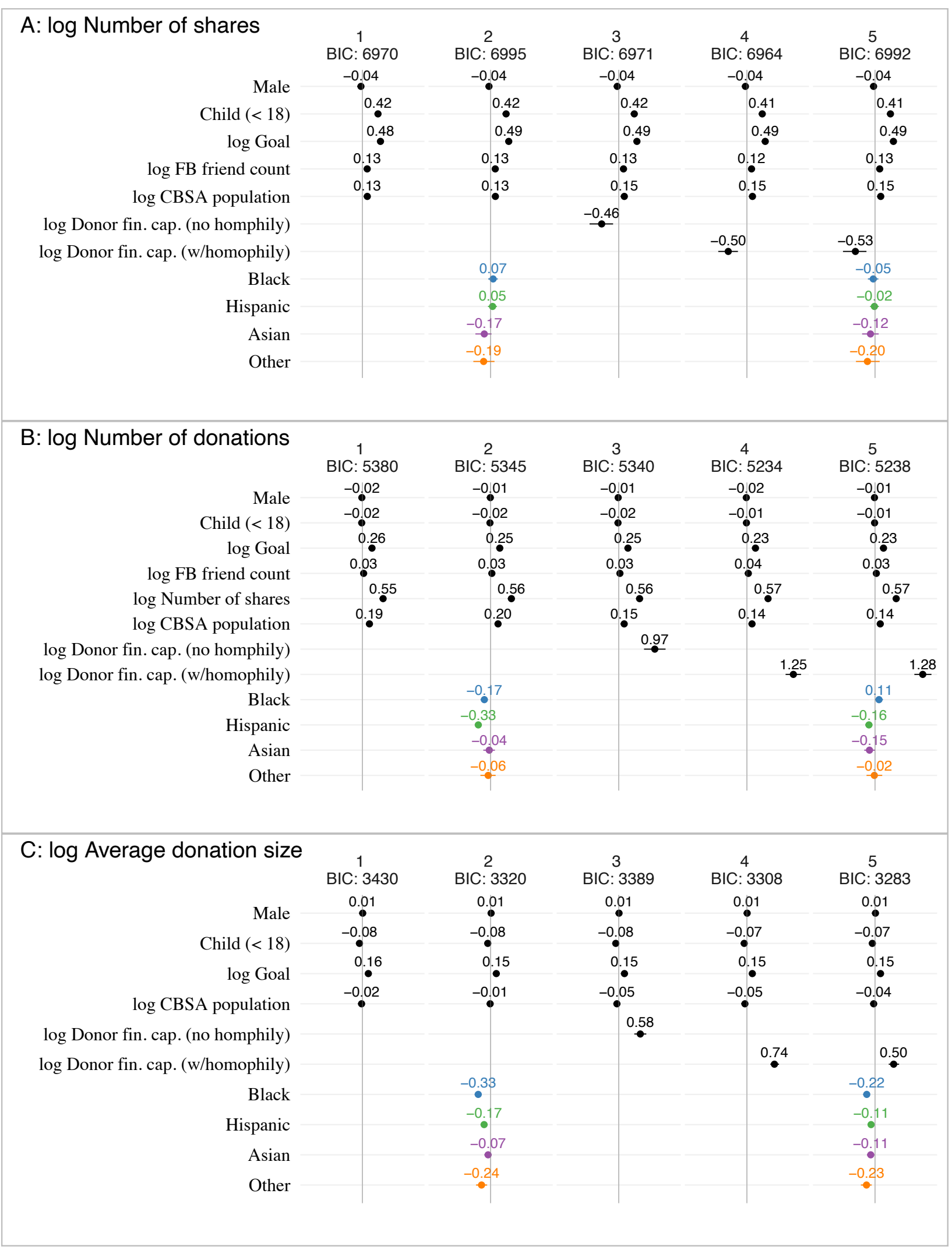

Figure 6: Summary of hierarchical linear models estimating log number of shares, log number of donations and log mean donation with bootstrap 95\% confidence intervals. 
Differences in returns by race and ethnicity are not explained by observed patterns in online social sharing. None of the models estimating rates of sharing, shown in panel A of Figure 6 , demonstrate significant differences in sharing by race or ethnicity. The models do present a striking and unanticipated result: the rate of sharing is negatively associated with estimated donor financial capacity for the campaign. These models support Hypothesis 1a, which posited that sharing does not vary by race and ethnicity, but disconfirm Hypothesis $1 \mathrm{~b}$, which posited that income levels of potential donors are unrelated to sharing. In fact, campaigns with lower income donor pools are shared more than those with higher income donor pools.

Because network access does not vary based on the race and ethnicity of the beneficiary, differences in returns must result from the number of donations for a given number of shares, the size of donations received from potential donors, or a combination of those factors. In the elasticity-based models shown in Figure 6 panel B, donor financial capacity is clearly associated with number of donations, with a $1 \%$ increase in donor financial capacity yielding more than a $1 \%$ increase in the number of donations in the best fitting model, perhaps reflecting a large number of potential donors who "come off the sidelines" above low income levels. In models that include donor financial capacity and beneficiary race, the coefficient associated with Black beneficiaries is statistically indistinguishable from zero. However, for Hispanic beneficiaries, the coefficient based on ethnicity remains and is highly significant, even when accounting for estimated donor income. Exponentiating the parameter shows that even after accounting for donor financial capacity Hispanic beneficiaries will be expected to receive approximately $15 \%$ fewer donations than White beneficiaries.

These models confirm Hypothesis 2, stating that the number of donations is correlated with network financial capacity. The role of racial and ethnic income inequality in generating unequal outcomes is demonstrated clearly by comparing models using estimates of financial capacity including estimated homophily to those where financial capacity is estimated using geography alone. The Bayesian Information Criterion (BIC) is a penalized goodness of fit measure. A decrease of 6 points in BIC indicates "strong" evidence, and 10 points "very strong" evidence that a covariate improves a model, independent of the magnitude of the BIC value (Raftery 1995). Models including estimates of donor financial capacity based on geographic income variation are clear improvements on models that include only controls. But accounting for the racial and ethnic composition of donor pools yields far superior model fits, with models using estimates of donor financial capacity based on the racial and ethnic composition of the donor pool yielding BICs 100 points lower than those estimated without accounting for income inequality by race and ethnicity.

Finally, we turn to the amount raised per donation, estimating the log mean donation amount for each campaign, shown in Figure 6 panel C. ${ }^{5}$ As expected, higher-income donor pools yield larger donations. In the best-fitting model, a one-percent increase in estimated donor financial capacity corresponds to a $0.75 \%$ percent increase in the average donation size.

Financial capacity estimates including income variation by race and ethnicity again provide far superior model fits to those based on geography alone. However, in contrast to the models of

\footnotetext{
${ }^{5}$ An equivalent model would estimate the log amount raised by the campaign with a covariate for the log number of donations: $\log ($ raised $)=\log ($ mean_donation*donation_count $)=\log ($ mean_donation $)+$ $\log ($ donation_count).
} 
donation counts, including estimates that account for racial differences in financial capacity shrinks but does not eliminate the estimated difference in donation size for Black beneficiaries. This is also true for Hispanic and "other race" beneficiaries; the changes in money raised are only partially explained by models that include estimates of donor financial capacity.

\section{Summary of Model Results}

Statistical models largely confirm hypotheses that geographic and racial differences in network financial capacity explain a substantial proportion of differences in returns by race and ethnicity. The race and ethnicity of the beneficiary is not associated with increased sharing of campaigns, supporting Hypothesis 1a, but network financial capacity seems to be inversely related to sharing, which is an unexpected result. Hypothesis 2, which asserted that network resources are a primary driver of the number of donations is also largely confirmed. The lower financial capacity of Black beneficiaries' networks relative to the richer networks of White beneficiaries explains the disparity in number of donations, but even after accounting for network income, Hispanic beneficiaries receive fewer donations. Hypothesis 3, which argues that the size of donations also depends on variation in income by race, ethnicity and location is also confirmed. In this case I also show that Black and Hispanic beneficiaries receive smaller donations than White and Asian beneficiaries, even after accounting for differences in donor resources.

\section{Robustness Checks}

One limitation of the data used for these analyses is that in a non-trivial number of cases, raters disagreed about the race, ethnicity or gender of the beneficiary. To assess whether my own assignment of race and ethnicity in ambiguous cases affected the results, I ran the full set of analyses using only the 1,957 campaigns where two independent raters agreed on the gender and race/ethnicity of the subject. Using this subset of data, results are substantively similar to those in the models using the whole dataset. The only notable differences were for 'other' race beneficiaries, which displayed significant negative coefficient for sharing, and larger drop in donation size in the models using a smaller data set. Given that this group had less than half the number of campaigns of any other race and ethnicity, it is not surprising that a small number of additional campaigns could affect estimates.

As a robustness check for my estimates of donor financial capacity, I compared financial capacity estimates created using social geography to those based on physical geography, using measures of donor financial capacity based on median incomes of CBSAs and Census "places" defined by city boundaries, with and without accounting for the racial and ethnic makeup of each donor pool. To test an assumption that income in the organizer's immediate neighborhood is highly correlated with donor financial capacity, I also evaluated estimates of financial capacity for residents in the ZCTA where the campaign was initiated, using median incomes for residents of the same race and ethnicity as the beneficiary and for all ZCTA residents. By BIC, reported with coefficients for financial capacity in Table 2, there is strong evidence that financial capacity estimates using the combination of social geography and estimated homophily provided better model fits than alternative measures using administrative geography. It is notable that the relationship between race and income is strong enough that when financial capacity estimates take homophily into account, coefficients are large and significant at $p<.001$ for all geographies. 
Table 2: Coefficients for alternate measures of donor financial capacity on money raised in models without covariates for beneficiary race. Bold text indicates best fit.

\begin{tabular}{|c|c|c|c|c|}
\hline \multirow[t]{2}{*}{ Geography } & & No Homophily & Estimated Homophily & Full Homophily \\
\hline & \multicolumn{4}{|c|}{ Models Estimating Funds Raised } \\
\hline \multirow[t]{2}{*}{ Social } & & $1.464 * * *$ & $1.783 * * *$ & $0.900 * * *$ \\
\hline & $\mathrm{BIC}$ & 7326 & 7232 & 7272 \\
\hline \multirow[t]{2}{*}{ CBSA } & & 0.467 & $1.670 * * *$ & $0.732 * * *$ \\
\hline & $\mathrm{BIC}$ & 7368 & 7258 & 7299 \\
\hline \multirow[t]{2}{*}{ Place } & & 0.187 & $1.094 * * *$ & $0.551 * * *$ \\
\hline & $\mathrm{BIC}$ & 7369 & 7278 & 7316 \\
\hline \multirow[t]{2}{*}{ ZCTA } & & $0.263 * * *$ & & $0.354 * * *$ \\
\hline & $\mathrm{BIC}$ & 7351 & & 7326 \\
\hline
\end{tabular}

\section{Discussion}

The "digital safety net" of online crowdfunding is not, fundamentally, digital: it is a safety net comprised of people, the connections between them, and the financial resources they can provide one another. When the distribution of financial resources is inequitable, crowdsourced funding can exacerbate that inequality. While results presented here fundamentally confirm prior research showing racial inequality in crowdsourced medical fundraising, the novel estimates of network financial capacity, derived from the geographic structure of online friendship links and the racial and ethnic composition of donor pools, demonstrate that returns to medical crowdfunding are highly dependent on the financial resources available to donors. When social networks are shaped by both geography and racial and ethnic homophily, underlying patterns of income inequality in the population will translate into lower returns for Black and Hispanic recipients than for White and Asian recipients.

My results show that differences in online sharing do not explain racial inequality in returns. Surprisingly, I find that that campaigns are shared more often when potential donors have lower access to financial capital. This result may indicate that potential donors who can't afford to donate money instead share online in order to show solidarity with the beneficiary. Online sharing of campaigns does not seem to be related to the race of the beneficiary, indicating that potential donors may not take race into account when judging who deserves help.

As I hypothesized, the amount of money available to potential donors is strongly associated with both the number of donations and the size of donations to campaigns. Variation in financial resources available to donors can fully account for differences in number of donations for Black recipients, and models show more than half of the deficit in donations for Hispanic recipients can be attributed to estimated financial capacity. The size of donations is also highly dependent on financial capacity, compounding the impact of social network resources on outcomes. Differences in estimated network financial capacity account for most of the deficit in average donation size to campaigns on behalf of Hispanic recipients, but a smaller proportion for Black recipients. Even after accounting for differences in network members' finances, significant gaps in mean donation size remain for both Black and Hispanic recipients. Overall, my estimate 
of donor financial capacity can explain most of the deficit for Black recipients, and almost half of the deficit for Hispanic recipients.

There are a number of limitations to my research. I found campaigns using GoFundMe's search interface, which uses proprietary algorithms that may introduce bias into the sample. Classification of race and ethnicity of beneficiaries was performed by online coders and may not reflect the perceptions of beneficiaries themselves or potential donors. Finally, my estimate of donor financial capacity is based on patterns of social network geography, race and median incomes at the ZCTA level along with donor surnames, rather than direct knowledge of the social networks of the individuals who create campaigns. However, the large and significant relationship between my measure of donor financial capacity and returns, along with consistent results using alternate measures of financial capacity, indicates that resources available to social connections have a real and substantial relationship to outcomes.

Though differences in network financial capacity may explain a large proportion of the gap in returns for Black and Hispanic recipients, it would be a mistake to conclude that racism does not play a role in inequity in returns. At the most direct level, we cannot rule out discrimination on the part of potential donors. Hispanic beneficiaries receive fewer donations and both Black and Hispanic beneficiaries receive smaller donations even after accounting for donor financial capacity. Just as employment discrimination is more apparent at the job offer stage than at the interview callback stage (Quillian, Lee, and Oliver 2020), crowdfunding discrimination may occur for donations, which are relatively costly, but not for sharing, which is free.

In any case, we cannot know the extent to which people might discriminate in situations they do not encounter. Historic and current racism in the job market, housing market and political institutions in the United States means that Black and Hispanic people tend to belong to networks with lower financial capacity than those of White people. My results show that these segregated social networks can "do the work" of perpetuating inequality by limiting access to resources to members of groups that already have them.

Going forward my work points toward a potentially rich vein of research that investigates crowdfunding as a social process. First, the impact of network financial resources on crowdfunding returns should be validated using simulation studies and Bayesian methods that incorporate uncertainty rather than relying on point estimates of income as my models do. Future research should also incorporate true random samples of the entire corpus of GoFundMe campaigns, including samples taken from rural areas where social networks may differ from those in urban areas.

Second, while financial capacity may be an important factor in shaping returns, socially constructed perceptions of deservingness determine how that financial capacity is deployed. My research does not explore how intersections of race, gender and class might affect perceptions of deservingness. Experimental vignette studies might be used to identify how combinations of race, gender and class affect responses to appeals, and whether the attributes that make a recipient appear deserving are in fact separable from markers of social class.

Sociologists should also study the effects of excessive reliance on network resources for support. Studies have noted how reliance on network support can lead to depleted social capital and defensive individualism in poor minority communities (Smith 2005, Lubbers, Small, and 
García 2020). Scholars should investigate how crowdfunding affects relationships and social cohesion in order to understand the broader social repercussions of the limited social safety net.

Ultimately, policy makers who seek to limit those social repercussions must address the burdens that cause people to reach out to the internet for help. Provision of universal, comprehensive, health insurance will limit the need to seek aid for emergent medical expenses. But insurance alone is likely insufficient for addressing unmet needs, as demonstrated by the widespread use of medical crowdfunding in Canada (Duynhoven 2019; Snyder 2017, 2020). If policy makers seek to allow communities to have equal success while using private safety nets, they will need to pursue policies that seek financial equality rather than merely amelioration of distress.

\section{References}

Alesina, Alberto, Edward L. Glaeser, and Burce Sacerdote. 2001. "Why Doesn't the United States Have a European-Style Welfare State?" Brookings Papers on Economic Activity 2001 (2): 187-277. https://doi.org/10.1353/eca.2001.0014.

Bailey, Michael, Rachel Cao, Theresa Kuchler, Johannes Stroebel, and Arlene Wong. 2018. "Social Connectedness: Measurement, Determinants, and Effects." Journal of Economic Perspectives 32 (3): 259-80. https://doi.org/10.1257/jep.32.3.259.

Bailey, Michael, Ruiqing (Rachel) Cao, Theresa Kuchler, Johannes Stroebel, and Arlene Wong. 2017. "Measuring Social Connectedness.” Working Paper 23608. Working Paper Series. National Bureau of Economic Research. https://doi.org/10.3386/w23608.

Bailey, Michael, Patrick Farrell, Theresa Kuchler, and Johannes Stroebel. 2019. "Social Connectedness in Urban Areas.” w26029. Cambridge, MA: National Bureau of Economic Research. https://doi.org/10.3386/w26029.

Barcelos, Chris A. 2019. “'Bye-Bye Boobies': Normativity, Deservingness and Medicalisation in Transgender Medical Crowdfunding." Culture, Health \& Sexuality 21 (12): 1394-1408. https://doi.org/10.1080/13691058.2019.1566971.

Berliner, Lauren S., and Nora J. Kenworthy. 2017. "Producing a Worthy Illness: Personal Crowdfunding amidst Financial Crisis." Social Science \& Medicine 187 (August): 23342. https://doi.org/10.1016/j.socscimed.2017.02.008.

Cohn, Nate, and Kevin Quealy. 2020. "How Public Opinion Has Moved on Black Lives Matter." The New York Times, June 10, 2020, sec. The Upshot. https:/www.nytimes.com/interactive/2020/06/10/upshot/black-lives-matterattitudes.html.

Collins, Sara R, Munira Z Gunja, and Michelle M Doty. 2017. "How Well Does Insurance Coverage Protect Consumers from Health Care Costs?" The Commonwealth Fund.

Detting, Lisa J., Joanne W. Hsu, Lindsay Jacobs, Kevin B. Moore, and Jeffrey P. Thompson. 2017. "Recent Trends in Wealth-Holding by Race and Ethnicity: Evidence from the Survey of Consumer Finances." FEDS Notes. Washington: Board of Governors of the Federal Reserve System. https://www.federalreserve.gov/econres/notes/feds-notes/recenttrends-in-wealth-holding-by-race-and-ethnicity-evidence-from-the-survey-of-consumerfinances-20170927.htm. 
DiPrete, Thomas A., Andrew Gelman, Tyler McCormick, Julien Teitler, and Tian Zheng. 2011. "Segregation in Social Networks Based on Acquaintanceship and Trust." American Journal of Sociology 116 (4): 1234-83. https://doi.org/10.1086/659100.

Duynhoven, Alysha van, Anthony Lee, Ross Michel, Jeremy Snyder, Valorie Crooks, Peter Chow-White, and Nadine Schuurman. 2019. "Spatially Exploring the Intersection of Socioeconomic Status and Canadian Cancer-Related Medical Crowdfunding Campaigns.” BMJ Open 9 (6): e026365. https://doi.org/10.1136/bmjopen-2018-026365.

Esping-Andersen, Gøsta. 1990. The Three Worlds of Welfare Capitalism. Princeton University Press.

Gilens, Martin. 1999. Why Americans Hate Welfare: Race, Media, and the Politics of Antipoverty Policy. Studies in Communication, Media, and Public Opinion. Chicago: University of Chicago Press.

GoFundMe. 2019a. "Creating a GoFundMe From Start to Finish.” GoFundMe Help Center. 2019. http://support.gofundme.com/hc/en-us/articles/360001992627-Creating-aGoFundMe-From-Start-to-Finish-.

—. 2019b. "Medical Fundraising - Start a Free Fundraiser." 2019. https://www.gofundme.com/start/medical-fundraising.

Granovetter, Mark. 1973. "The Strength of Weak Ties.” American Journal of Sociology 78 (6): 1360-1380.

- (1974) 1995. Getting a Job: A Study of Contacts and Careers. 2nd edition. Chicago: The University Of Chicago Press.

Hacker, Jacob S. 2008. The Great Risk Shift: The New Economic Insecurity and the Decline of the American Dream. Revised, Updated edition. Oxford: Oxford University Press, U.S.A.

Harris, Ainsley. 2017. "How Crowdfunding Platform GoFundMe Has Created A \$3 Billion Digital Safety Net." Fast Company. February 13, 2017.

https://www.fastcompany.com/3067472/how-crowdfunding-platform-gofundme-hascreated-a-3-billion-digital.

Katznelson, Ira. 2014. Fear Itself: The New Deal and the Origins of Our Time. $1^{\text {st }}$ edition. New York, NY: Liveright.

Kenworthy, Nora J. 2019. "Crowdfunding and Global Health Disparities: An Exploratory Conceptual and Empirical Analysis.” Globalization and Health 15 (S1): 71. https://doi.org/10.1186/s12992-019-0519-1.

Kenworthy, Nora J., Zhihang Dong, Anne Montgomery, Emily Fuller, and Lauren Berliner. 2020. "A Cross-Sectional Study of Social Inequities in Medical Crowdfunding Campaigns in the United States." PLOS ONE, March. http://arxiv.org/abs/1908.11018.

Lee, Sumin, and Vili Lehdonvirta. 2020. "New Digital Safety Net or Just More 'Friendfunding'? Institutional Analysis of Medical Crowdfunding in the United States." Information, Communication \& Society. doi: 10.1080/1369118X.2020.1850838.

Loeb, Stacy, Sorab Taneja, Dawn Walter, Sarah Zweifach, and Nataliya Byrne. 2018. "Crowdfunding for Prostate Cancer and Breast Cancer." BJU International 122 (5): 72325. https://doi.org/10.1111/bju.14408.

Lubbers, Miranda J., Mario Luis Small, and Hugo Valenzuela García. 2020. "Do Networks Help People To Manage Poverty? Perspectives from the Field." The ANNALS of the American Academy of Political and Social Science 689(1):7-25. doi: 10.1177/0002716220923959. 
McDonald, Steve. 2011. "What's in the 'Old Boys' Network? Accessing Social Capital in Gendered and Racialized Networks." Social Networks 33 (4): 317-30. https://doi.org/10.1016/j.socnet.2011.10.002.

McDonald, Steve, Lindsay Hamm, James R. Elliott, and Pete Knepper. 2016. "Race, Place, and Unsolicited Job Leads: How the Ethnoracial Structure of Local Labor Markets Shapes Employment Opportunities." Social Currents 3 (2): 118-37. https://doi.org/10.1177/2329496515620645.

McDonald, Steve, Nan Lin, and Dan Ao. 2009. "Networks of Opportunity: Gender, Race, and Job Leads." Social Problems 56 (3): 385-402. https://doi.org/10.1525/sp.2009.56.3.385.

McPherson, Miller, Lynn Smith-Lovin, and James M Cook. 2001. "Birds of a Feather: Homophily in Social Networks." Annual Review of Sociology 27 (1): 415-44. https://doi.org/10.1146/annurev.soc.27.1.415.

Moody, James. 2001. "Race, School Integration, and Friendship Segregation in America." American Journal of Sociology 107 (3): 679-716. https://doi.org/10.1086/338954.

Morgan, Kimberly J., and Andrea Louise Campbell. 2011. The Delegated Welfare State: Medicare, Markets, and the Governance of Social Policy. Oxford University Press.

Pager, Devah. 2003. "The Mark of a Criminal Record.” American Journal of Sociology 108 (5): 937-75. https://doi.org/10.1086/374403.

Pager, Devah, and Hana Shepherd. 2008. "The Sociology of Discrimination: Racial Discrimination in Employment, Housing, Credit, and Consumer Markets." Annual Review of Sociology 34 (1): 181-209. https://doi.org/10.1146/annurev.soc.33.040406.131740.

Pedulla, David S., and Devah Pager. 2019. "Race and Networks in the Job Search Process." American Sociological Review, November. https://doi.org/10.1177/0003122419883255.

Portes, Alejandro, and Julia Sensenbrenner. 1993. "Embeddedness and Immigration: Notes on the Social Determinants of Economic Action." American Journal of Sociology 98(6):1320-50.

Quillian, Lincoln, John J. Lee, and Mariana Oliver. 2020. "Evidence from Field Experiments in Hiring Shows Substantial Additional Racial Discrimination after the Callback.” Social Forces 98 (4). https://doi.org/10.1093/sf/soaa026.

Quillian, Lincoln, Devah Pager, Ole Hexel, and Arnfinn Haagensen Midtbøen. 2017. "MetaAnalysis of Field Experiments Shows No Change in Racial Discrimination in Hiring over Time." Proceedings of the National Academy of Sciences of the United States of America. https://doi.org/10.1073/pnas.1706255114.

Raftery, Adrian E. 1995. "Bayesian Model Selection in Social Research." Sociological Methodology 25: 111. https://doi.org/10.2307/271063.

Silva, Fabiana. 2018. "The Strength of Whites' Ties: How Employers Reward the Referrals of Black and White Jobseekers." Social Forces 97 (2): 741-68. https://doi.org/10.1093/sf/soy051.

Skocpol, Theda. 1992. Protecting Soldiers and Mothers the Political Origins of Social Policy in the United States. Cambridge, MA: Belknap Press of Harvard University Press. - 1995. “6. African Americans in U.S. Social Policy.” In Classifying by Race, edited by Paul E. Peterson, 129-55. Princeton: Princeton University Press. https://doi.org/10.1515/9781400864102.129. . 2012. The Tea Party and the Remaking of Republican Conservatism. New York: Oxford University Press. 
https://www.oxfordscholarship.com/view/10.1093/acprof:osobl/9780199832637.001.000 1/acprof-9780199832637.

Smith, Jeffrey A., Miller McPherson, and Lynn Smith-Lovin. 2014. "Social Distance in the United States: Sex, Race, Religion, Age, and Education Homophily among Confidants, 1985 to 2004." American Sociological Review 79 (3): 432-56. https://doi.org/10.1177/0003122414531776.

Smith, Sandra. 2000. "Mobilizing Social Resources: Race, Ethnic, and Gender Differences in Social Capital and Persisting Wage Inequalities." The Sociological Quarterly 41 (4): 509-37.

2005. "'Don't Put My Name on It': Social Capital Activation and Job-Finding Assistance among the Black Urban Poor." American Journal of Sociology 111 (1): 1-57. https://doi.org/10.1086/428814.

Snyder, Jeremy, Annalise Mathers, and Valorie A. Crooks. 2016. "Fund My Treatment!: A Call for Ethics-Focused Social Science Research into the Use of Crowdfunding for Medical Care." Social Science \& Medicine 169 (November): 27-30. https://doi.org/10.1016/j.socscimed.2016.09.024.

Snyder, Jeremy, Valorie A. Crooks, Annalise Mathers, and Peter Chow-White. 2017. “Appealing to the Crowd: Ethical Justifications in Canadian Medical Crowdfunding Campaigns." Journal of Medical Ethics 43(6):364-67. doi: 10.1136/medethics-2016-103933.

Snyder, Jeremy. 2020. Exploiting Hope: How the Promise of New Medical Interventions Sustains Us--and Makes Us Vulnerable. Oxford University Press.

Stack, Carol B. 1975. All Our Kin: Strategies for Survival in a Black Community. Basic Books. Trattner, Walter. 1998. From Poor Law to Welfare State, 6th Edition. Simon and Schuster. U.S. Census Bureau. 2018. "Income and Poverty in the United States: 2017," September, 74.

Wimmer, Andreas, and Kevin Lewis. 2010. "Beyond and Below Racial Homophily: ERG Models of a Friendship Network Documented on Facebook." American Journal of Sociology 116 (2): 583-642. https://doi.org/10.1086/653658.

Young, Michael J., and Ethan Scheinberg. 2017. "The Rise of Crowdfunding for Medical Care: Promises and Perils." JAMA 317 (16): 1623-24. https://doi.org/10.1001/jama.2017.3078.

Zelizer, Viviana A. 1994. Pricing the Priceless Child: The Changing Social Value of Children. Princeton University Press. 1997. The Social Meaning of Money. New York: BasicBooks. 